\title{
Use of Oligonucleotide Probes Directed Against T Cell Antigen Receptor Gamma Delta Variable-(Diversity)-Joining Junctional Sequences as a General Method for Detecting Minimal Residual Disease in Acute Lymphoblastic Leukemias
}

\author{
Elisabeth A. Macintyre," Luc d’Auriol, ${ }^{\prime}$ Nelly Duparc, * Guy Leverger, $\$$ Francis Galibert, ${ }^{\ddagger}$ and François Sigaux* \\ *The Molecular Hematology and Central Hematology Laboratories, ${ }^{\ddagger}$ the Centre National de la Recherche Scientifique UPR 38, and \\ Hematology Department, Saint-Louis Hospital 2, 75475, Paris Cedex 10, France
}

\section{Abstract}

To provide a sensitive and generally applicable method to detect clonal cells in acute lymphoblastic leukemias (ALL), we have designed a new strategy based on the polymerase chain reaction (PCR) amplification of the $T$ cell receptor $\gamma \delta$ gene rearrangements found in most $T$ and $B$ lineage ALLs. PCR allows rapid sequencing of variable-(diversity)-joining ( $\mathrm{V}-[\mathrm{D}]-$ J) junctions from tumor DNA and construction of anti-junctional oligonucleotides (AJOs) used as probes to detect clonal cells in the same patient. We have defined oligonucleotides suitable for all $\mathrm{T}$ cell receptor (TCR) rearrangements involving functional $\mathrm{V} \boldsymbol{\gamma}$ segments. Oligonucleotides corresponding to preferential TCR $\delta$ rearrangements in T and B lineage ALLs were also used. By analysis of the nucleotide sequence of 52 $\mathrm{V} \boldsymbol{\gamma}-\mathrm{V} \boldsymbol{\gamma}$ junctions from 30 cases of $B$ and $T$ ALLs, we demonstrate that $\mathrm{V}-\mathrm{J}$ junctional sequences are clone specific in both lineages and at all stages of differentiation examined despite the frequent presence of the recently described $P$ nucleotides. Experiments performed with TCR $\gamma \delta$ AJOs on DNA from tumor cells and polyclonal $\mathrm{T}$ cells show that AJOs can be used to differentiate clonal cells from polyclonal $T$ cells, distinguish between different $T$ cell clones, and detect residual clonal populations at $10^{-4} / 10^{-5}$ dilution. AJOs were also used to detect residual disease in samples from patients in clinical and morphological complete remission. Finally, rearrangement patterns were studied by classical Southern analysis in selected cases at both presentation and subsequent relapse showing absence of clonal evolution in most cases. V-(D)-J nucleotide sequences of rearrangements with an identical pattern of rearrangement at presentation and relapse were identical in all cases analyzed. We therefore describe a new, specific, and clinically useful strategy for the detection of minor clonal populations applicable in the majority of cases of ALL. (J. Clin. Invest. 1990. 86:2125-2135.) Key words: acute leukemias • minimal residual disease $\cdot \mathbf{T}$ cell receptor genes $\bullet$ polymerase chain reaction $\bullet$ molecular medicine

Address correspondence and reprint requests to F. Sigaux, Molecular Hematology Laboratory, Saint-Louis Hospital 2, Place du Docteur Fournier, 75475, Paris Cedex 10, France. L. d'Auriol's present address is GENSET, Hall des Biotechnologies, Univerite Paris VII, 2 place Jussieu, 75005, Paris, France.

Received for publication 16 February 1990 and in revised form 25 July 1990.

J. Clin. Invest.

(C) The American Society for Clinical Investigation, Inc.

$0021-9738 / 90 / 12 / 2125 / 11 \$ 2.00$

Volume 86, December 1990, 2125-2135

\section{Introduction}

The detection of minimal residual disease (MRD) ${ }^{1}$ in the lymphoid malignancies is of fundamental importance, both in the clinical management of patients, and in order to improve our understanding of the mechanisms whereby the immune system deals with low numbers of tumor cells. Improved techniques will allow better assessment of complete remission after chemotherapy, earlier detection of relapse, and improved analysis of the role of immune modulators in apparent complete remission. In addition, the use of autologous bone marrow transplantation is, at least theoretically, dependent on the reinfusion of bone marrow that is free of disease. Currently available methods are limited either by their sensitivity or specificity and improved techniques are clearly required (1).

The demonstration of immunoglobin or T cell receptor $\beta$ gene rearrangements has provided useful markers of clonality in lymphoid malignancies (2), but their detection by Southern blot analysis is in general limited to $1-5 \%$. The recent development of the polymerase chain reaction (PCR) (3) has allowed detection of a much lower level of tumor infiltration in certain hematological malignancies. This technique has been used to amplify and detect specific chromosomal translocations with a level of sensitivity of detection of $\sim 1$ in $10^{5}$. It has thus been possible to detect residual clonal cells in those cases of predominantly low grade follicular, non-Hodgkin lymphomas that demonstrate a $t(14 ; 18)(4)$ and to detect low levels of $t(9 ; 22)$. RNA from cases of chronic myeloid leukemia or $t(9 ; 22)$ positive acute lymphoblastic leukemia (ALL) in apparent complete remission (5).

The majority of lymphoid malignancies are not however, associated with a chromosomal translocation that has been characterized at the molecular level or that is suitable for PCR amplification. In contrast, the vast majority of these neoplasms are associated with clonal rearrangements of their antigen receptor genes, the structures and patterns of rearrangement of which have been extensively studied. We have undertaken to develop a system of PCR amplification of such clonal markers that would be useable in the majority of cases of ALL. In the germline state these genes exist as discontinuous $\mathrm{V}$ (variable), $\mathrm{J}$ (joining), and in some cases, $\mathrm{D}$ (diversity) segments (Fig. $1 A$ ). During early lymphoid differentiation these gene segments rearrange to generate antigen receptor diversity by two main mechanisms (6): (a) combinatorial diversity due to random recombination of segments and $(b)$ junctional diver-

1. Abbreviations used in this paper: AJO, antijunctional oligonucleotides; ALL, acute Lymphoblastic leukemia; D, diversity segment; J, joining segment; MRD, minimal residual disease; PCR, polymerase chain reaction; TCR, $T$ cell receptor; $V$, variable segment. 
Q

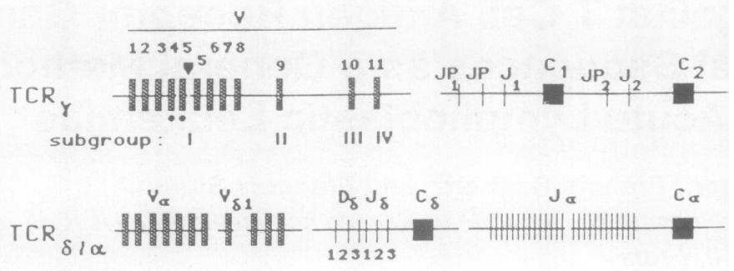

$\mathbf{B}$
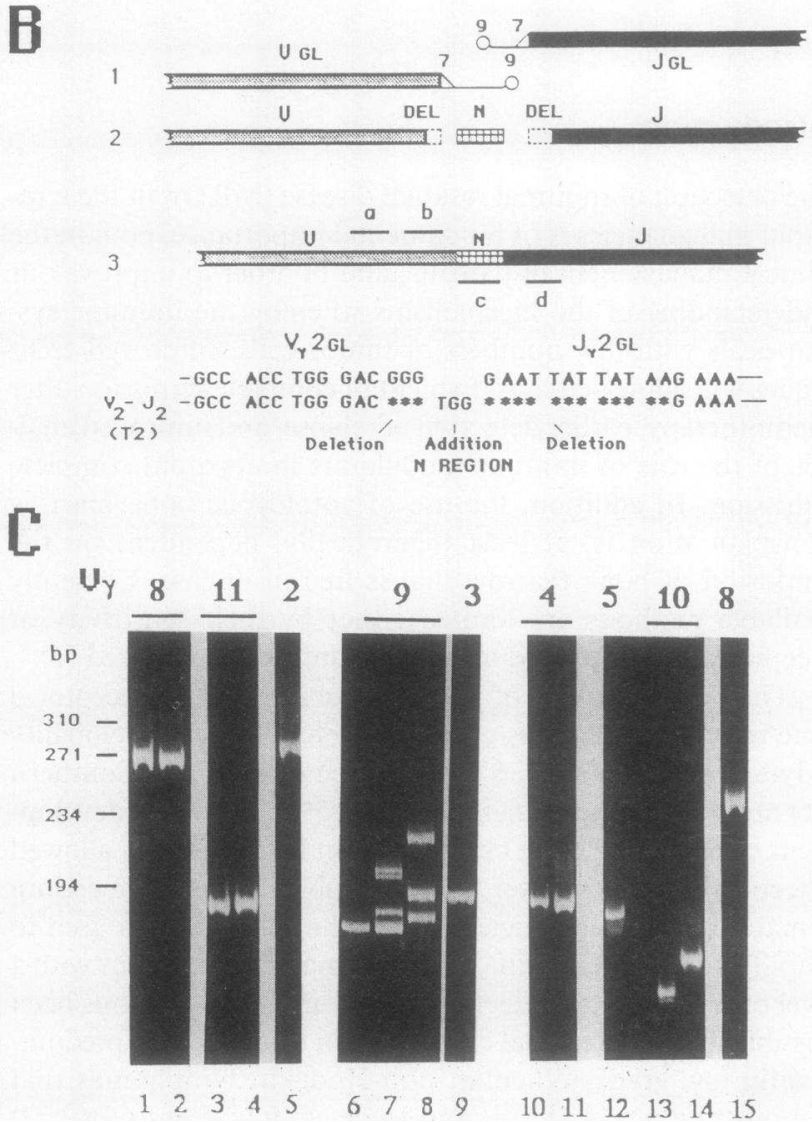

Figure 1. In vitro amplification of $\mathrm{TCR} \gamma$ rearrangements. (1A) Schematic representation of the TCR $\gamma$ and $\operatorname{TCR} \alpha / \delta$ loci. $V$, variable segments; $J$, joining segments; $D$, diversity segments. ( $1 B$ ) Junctional diversity. 1: germline configuration. 7 , heptamer; 9 , nonamer from the recognition sequences. 2: Schematic representation of the random deletions and additions occuring during rearrangements. For simplicity, P nucleotides (34) are not included in this schema. 3: actual configuration and strategy of PCR amplification. Oligonucleotides $a$ and $d$ are used as amplimers. Oligonucleotide $b$ is used as a probe to verify the specificity of amplification and as primer for sequencing; oligonucleotide $c$ is the AJO. A representative $\mathrm{V} \gamma 2-\mathrm{J} \gamma 2$ rearrangement occuring in a T ALL (case $T 2$ ) is shown. Note extensive nucleotide deletion of the $\mathrm{J} \gamma$ segment. (IC) Representative experiments of PCR amplification with the rearranged $\mathrm{V} \gamma$ segment indicated at the top of the lanes: $1, \mathrm{~T} 7 ; 2, \mathrm{~T} 42 ; 3, \mathrm{~T} 7 ; 4, \mathrm{~T} 41 ; 5, \mathrm{~B} 30 ; 6$, T37 (V9-JP); 7, B25; 8, B23; 9, T28; 10, T2; 11, T42; 12, T19; 13, T14; 14, T13; 15, T21 (V8-JP1). Primers corresponding to the rearranged $\mathrm{V}$ segment were used in the PCR reaction. The $\mathrm{J} \gamma 1 / 2$ primer was used in all cases with the exception of T37 (JP primer used) and T21 (JP1/2 used).

sity due to imprecise $\mathrm{V}$-(D)-J joining and random addition of nongermline encoded nucleotides by the TdT enzyme to form the so-called $\mathrm{N}$ regions (Fig. $1 \mathrm{~B}$ ). We reasoned that if such random junctional sequences are clone-specific markers, a strategy based on PCR amplification of rearrangements by $V$ and $J$ primers followed by detection with specific antijunctional oligonucleotides (AJOs) could be useful for the detection of minor clonal lymphoid populations. Analysis of acute lymphoid leukemias for the detection of minimal residual disease is well adapted to this strategy. Enriched populations of blast cells can be obtained at presentation in the majority of cases, thus allowing the construction of a clone-specific probe that recognizes the junctional sequence and would be able, at least in theory, to distinguish this sequence from those peripheral $\mathrm{T}$ cells using the same $\mathrm{V}-\mathrm{J}$ combination. This probe is then used on samples obtained during the evolution of the disease. Although this strategy is theoretically adaptable to all rearranging genes, some limitations restrict the choice of genes to be studied. Rearrangements of immunoglobin or TCR genes occur in almost all lymphoid neoplasms but the Ig heavy and light chain and the TCR $\alpha$ and $\beta$ chain genes do not represent ideal targets for PCR amplification, since the large number of variable and joining segments that undergo rearrangement (reviewed in reference 7) make the assignment of $\mathbf{V}$ and $\mathrm{J}$ segment utilization and the development of suitable oligonucleotide primers a practical problem. Consensus primers directed against framework sequences shared by many rearranging segments as amplimers can be used to overcome this problem but, at least for the genes we have tested (i.e., TCR $\gamma$ and TCR $\delta$ ), this leads to a decrease of sensitivity of detection when clonal cells are mixed with polyclonal cells (see below).

The TCR $\gamma$ and $\delta$ genes are, in contrast, ideal targets for PCR based detection of minimal residual disease, since they are characterized by a limited germline encoded repertoire and by extensive junctional diversity (8) (Fig. $1 A$ ). TCR $\gamma$ contains $15 \mathrm{~V}$ segments, only 10 of which have been shown to undergo rearrangement. These rearranging $\mathrm{V}$ segments can be subdivided into those belonging to the $\mathrm{V} \gamma \mathrm{I}$ family $\left(\mathrm{V}_{\gamma} 2,3,4,5,8\right)$ and the $\mathrm{V}_{\gamma}$ II $\left(\mathrm{V}_{\gamma}\right.$ 9), $\mathrm{V}_{\gamma}$ III $\left(\mathrm{V}_{\gamma} 10\right)$, and $\mathrm{V}_{\gamma} \mathrm{IV}\left(\mathrm{V}_{\gamma} 11\right)$ families (9-14). The highest levels of homology exist between $V \gamma 2$ and $\mathrm{V}_{\gamma} 4, \mathrm{~V}_{\gamma} 3$ and $\mathrm{V}_{\gamma} 5$, since they represent recent duplication events (14). Of the $5 \mathrm{~J}$ segments $(9,15-17)$, two highly homologous segments $(\mathrm{J} \gamma 1$ and $\mathrm{J} \gamma 2)$ are used in the vast majority of $\mathrm{T}$ and B lineage ALLs (11). The nucleotide sequences of all these $\mathrm{V}$ and $\mathrm{J}$ segments are known (see Table II for reference). The TcR $\delta$ locus is also well characterized. To date, $6 \mathrm{~V}, 3 \mathrm{D}, 3$ $\mathrm{J}$ segments, and 1 constant region have been described $(18-22)$. The TcR $\delta$ genes are localized on chromosome 14 (band q11) and are situated within the TcR $\alpha$ gene between the $\mathrm{V}$ and $\mathrm{J}$ regions (19, 21-24). TCR $\alpha$ rearrangement is therefore associated with TCR $\delta$ deletion on that allele. Due to the limited combinatorial diversity of TCR $\gamma \delta$ genes, $V$ and $J$ segment utilization and the choice of amplification primers can be determined from the pattern of DNA restriction fragments observed on Southern blot analysis using a limited number of probes and restriction endonuclease digests (12). In contrast to the limited germline encoded diversity, extensive junctional diversity has been demonstrated in TCR $\gamma$ and TCR $\delta$ rearrangements by analysis of thymocyte and peripheral $\mathrm{T}$ cell libraries (25-27). TCR $\gamma \delta$ junctional sequences are therefore theoretically suitable to detection by sequence-specific probes. Finally, it is now well established that TCR $\gamma \delta$ genes are rearranged (or in the case of TCR $\delta$ deleted) not only in almost all cases of T ALL, but also in a considerable proportion of ALLs 
Table I. TCR Gamma Junctional Nucleotide Sequences

\begin{tabular}{|c|c|c|c|c|c|c|c|c|c|}
\hline Case & Stage ${ }^{*}$ & \multicolumn{4}{|c|}{ First allele } & \multicolumn{4}{|c|}{ Second allele } \\
\hline & & & $b p$ & & $b p$ & & $b p$ & & $b p$ \\
\hline \multicolumn{10}{|c|}{$\mathrm{T}$ cell acute leukemias } \\
\hline $\mathrm{T} 2$ & I & V4 & 0 & $\underline{\text { CTAGGGTT }}$ & 3 & V2 & 3 & TGG & 12 \\
\hline T39 & I & V8 & 8 & CGCGGGTCTTCG & 10 & V8 & 5 & TTA & 4 \\
\hline $\mathrm{T} 7$ & II & V8 & 3 & $G$ & 8 & V11 & 12 & CGAATATA & 8 \\
\hline $\mathrm{T} 10$ & II & V4 & 5 & TTAAG & 4 & V9 & 3 & A & 5 \\
\hline $\mathrm{T} 12$ & II & V2 & 3 & & 3 & V4 & 4 & ATT & 2 \\
\hline $\mathrm{T} 13$ & II & V2 & 6 & TGGGAA & 7 & V10 & 8 & GAGCE & 0 \\
\hline T14 & II & V4 & 3 & CTC & 2 & V10 & 8 & GTATGGGTGT & 19 \\
\hline T24 & II & V4 & 4 & CGAAATC & 0 & V4 & 0 & GGGGGGTC & 0 \\
\hline T41 & II & V5 & 3 & CGACGATTT & 1 & V11 & 8 & AGGTTGGGG & 12 \\
\hline $\mathrm{T} 42$ & II & V8 & 10 & ACAGA & 8 & V4 & 0 & CETTTGTTTCGG & 8 \\
\hline T44 & II & V2 & 0 & $\underline{\text { CCGGGCT }}$ & 6 & $\psi \mathrm{V} 7$ & & & \\
\hline $\mathrm{T} 18$ & III & V2 & 0 & CCAGTTTGCTATGAGGA & 10 & V11 & 8 & GATGGAG & 10 \\
\hline T26 & III & V4 & 4 & CGACTACG & 12 & G & & & \\
\hline T25 & III & V2 & 0 & GTT & 1 & V4 & 2 & TGG & 7 \\
\hline T19 & $\gamma \delta$ & V5 & 1 & $\mathrm{C} \underline{\mathrm{C}}$ & 0 & V8? & & & \\
\hline $\mathrm{T} 21$ & $\gamma \delta$ & V2" & 4 & GGGG & 8 & V8\$ & 14 & GGG & 8 \\
\hline T31 & $\gamma \delta$ & V8 & 3 & TT & 6 & V8 & 5 & GGCGC & 5 \\
\hline T37 & $\gamma \delta$ & V9' & 0 & & 4 & G & & & \\
\hline $\mathrm{T} 15$ & $\alpha \beta$ & V5 & 3 & GCCCCGGG & 10 & V8 & 0 & AGAT & 3 \\
\hline B7 & III/IV & V9 & 0 & CAGG & 11 & G & & & \\
\hline B21 & IV & V9 & 10 & TCCC & 5 & G & & & \\
\hline B29 & IV & V2 & 0 & $\underline{\text { CCCG }}$ & 12 & G & & & \\
\hline
\end{tabular}

* T-ALL: I, CD3-CD4-CD8-CD1-; II, CD3- and at least one of the CD4, CD8, CD1 molecules expressed; III, CD3+ heterodimer ( $\alpha \beta$ or $\gamma \delta$ ) not determined; $\alpha \beta$, cells expressing the CD3-TCR $\alpha \beta ; \gamma \delta$, cells expressing the CD3-TCR $\gamma \delta$. B cell ALLs. III, CD19+CD10+CD20-; IV, $\mathrm{CD} 19+\mathrm{CD} 10+\mathrm{CD} 20+$. For a more detailed phenotype see references 28,30 , and 32 . $\ddagger \mathrm{J} \gamma 1$ or $\mathrm{J} \gamma 2$ segments were used in all cases unless stated otherwise. \$ Including N and P nucleotides (34). P nucleotides are underlined. " Rearranged to JP1; 'rearranged to JP (see Fig. 1). " R, rearrangement not assigned; $G$, germinal configuration. Del $V$, number of nucleotides deleted from the $3^{\prime}$ part of the $\mathrm{V}$ segment; del $\mathrm{J}$, number of nucleotides deleted from the $5^{\prime}$ part of the $J$ segment.

of B lineage, implying that diagnostic tools based on these rearrangements are of general interest in ALL. TCR $\gamma$ genes are rearranged on at least one allele in $40-70 \%$ of cases of $B$ lineage ALL including common CD10+ ALL. TCR $\delta$ genes are rearranged or deleted in $90 \%$ of $\mathrm{T} \mathrm{ALL}$ and in $70-100 \%$ of $B$ lineage ALL (28-30).

We have previously shown in a preliminary report (31) that PCR amplification of a particular TCR $\gamma$ rearrangement (i.e., $\mathrm{V} \gamma$ 9-J $\gamma$ ) in two cases of ALL, followed by cloning and sequencing of the V-J junction, allowed the construction of an antijunctional oligonucleotide (AJO) and its use to detect clonal cells at a $10^{-5}$ dilution into germline DNA. However, the $\mathrm{V} \gamma 9$ segment analyzed in this study is the sole member of the $\mathrm{V} \gamma$ II subgroup representing only $10 \%$ of rearrangements in ALLs according to our experience. It therefore remained to demonstrate that this strategy would be generally applicable in all TCR $\gamma$ rearrangements, particularly in those cases undergoing rearrangements involving the highly homogenous members of the $\mathrm{V} \boldsymbol{\gamma} \mathrm{I}$ family.

In this study, we have analyzed the $\mathrm{V}-(\mathrm{D})-\mathrm{J}$ junctions from a series of $T$ and $B$ lineage ALLs using PCR amplification and direct nucleotide sequencing. We show that a strategy based on AJOs is generally applicable to all cases of $\mathrm{T}$ and B lineage ALLs undergoing TCR $\gamma$ rearrangement and those T-ALL 
cases undergoing the preferential $\mathrm{V} \delta 1-\mathrm{J} \delta 1$ rearrangement (30). We also report that the method can be rendered more rapid by using double-stranded sequence analysis. Finally, we demonstrate the general specificity sensitivity and clinical applicability of the use of AJO's for the detection of clonal lymphoid populations.

\section{Methods}

Cells. DNA from 23 cases of T-ALL and 7 cases of B lineage ALL were analyzed (Table I). All cases were defined by standard morphological criteria, with all T-ALLs expressing the CD7 antigen and the B lineage cases the CD19 molecule. Full immunophenotypic characterization has been described elsewhere $(28,30,32)$, where relevant patient numbers correspond to those in previous publications. Polyclonal $\mathrm{T}$ cells were obtained by density gradient centrifugation on Ficoll Hypaque and classical sheep red blood cell rosetting.

Southern analysis of $T C R \gamma \delta$ rearrangements. Southern blots and study of rearrangements were performed using $\mathrm{J} \gamma$ and $\mathrm{J} \delta$ probes on Bam HI, Hind III, Eco RI, and Kpn I digests (30). Analysis of $\mathrm{V \gamma}$ rearrangements was performed as previously described (11) using $\mathrm{J} \gamma$ and specific $\mathrm{V} \gamma$ probes, and the $\mathrm{V}$ and $\mathrm{J}$ segments involved determined from the patterns obtained.

PCR amplification. PCR amplification of $1 \mu \mathrm{g}$ DNA was performed for 35 cycles, using the strategy previously described (33), using $\mathrm{V}$ and $\mathrm{J}$ primers specific for the segments shown to be involved on Southern blot analysis (Table II). As use of $\mathrm{J} \gamma 1$ vs. $\mathrm{J} \gamma 2$ is sometimes difficult to define (28) and as the nucleotide sequences of these segments are nearly identical, a common oligonucleotide (J 2 2S2) has been used as primer. A common $\mathrm{J} \gamma \mathrm{P} 1 / 2$ oligonucleotide has been used for JP1 and JP2 rearrangements. The quantity of oligonucleotide used for amplification of presentation DNA was $10 \mathrm{pm}$ each and for detection of minimal residual disease was $30-40 \mathrm{pm}$, since we have found that the lower concentration is more specific but insufficiently sensitive for the detection of rare events (data not shown). Polyclonal T cell control DNA was included to exclude the possibility that use of the slightly higher concentration of oligonucleotides led to nonspecific false positive responses. The temperature of annealing corresponded to the lower temperature of the two oligonucleotides used $\left(55-57^{\circ} \mathrm{C}\right)$. After amplification, samples were analyzed by $6 \%$ PAGE and ethidium bromide staining and by dot blot hybridization with ${ }^{32} \mathrm{P}$-labeled probes as previously described (33). In all cases the specificity of amplification was confirmed by verification of the $\mathrm{V} \gamma / \mathrm{V} \delta$ segment involved both by using $\mathrm{V} \gamma / \mathrm{V} \delta$ specific internal primer prefaced by $T$ in Table II as sequencing primers, and directly from the $\mathrm{V}_{\gamma} / \mathrm{V} \delta$ sequence data obtained. Separation of biallelic rearrangements on PAGE was performed by excision of the ethidium bromide-stained band and direct reamplification of $25 \%$ of the excised gel block for 15 cycles.

Sequences analysis. Direct double-stranded sequencing was performed as previously described (33) using 20-30 $\mathrm{ng} \mathrm{V \gamma}$-specific internal primers ( $\mathrm{TV} \gamma$ in Table II) $5^{\prime}$ labeled with ${ }^{32} \mathrm{P}$. In selected cases sequencing was performed after cloning of amplified products into M13 blunted, using 5' kinased oligonucleotides. Sequencing was performed by the sequenase method using $\mathrm{V}_{\gamma}$ and $\mathrm{J} \gamma 1 / 2$ internal primers and ${ }^{35}$ S-ATP. All sequences were performed on at least two occasions from separate PCR reactions.

Table II. Oligonucleotides

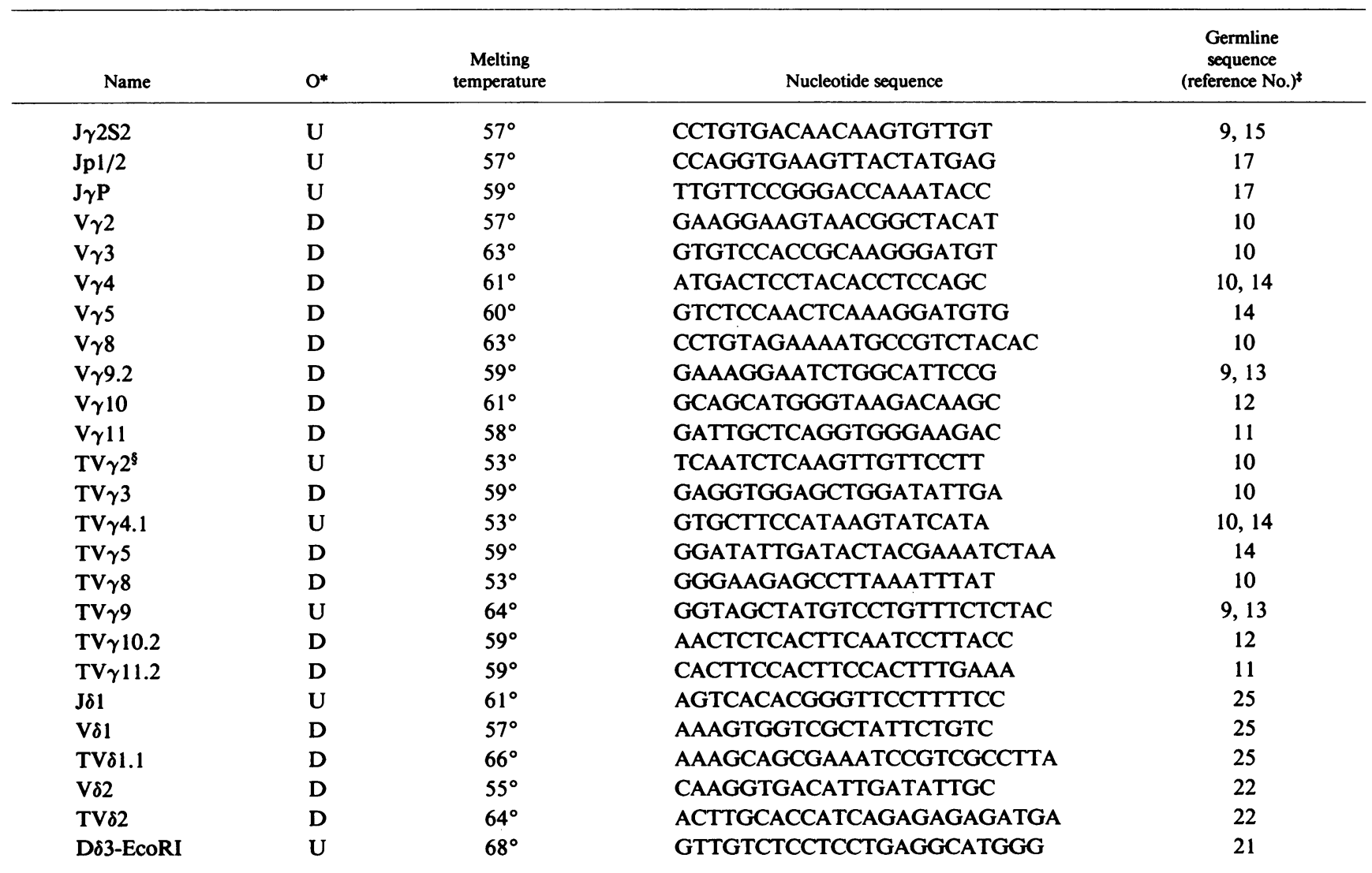

* Orientation by reference to transcription. U, Upstream; D, downstream. ${ }^{\ddagger}$ The list of references is not exhaustive; ${ }^{\circ}$ Oligonucleotides prefaced with a $\mathrm{T}$ were used as probes for hybridization and/or sequencing as was $\mathrm{J} \gamma 2 \mathrm{~S} 2$ in selected cases. All others were used as PCR primers. 
Oligonucleotide synthesis was performed according to standard methods.

\section{Results}

All $T C R \gamma$ rearrangements can be PCR amplified. The final aim of this study was to provide a highly sensitive and specific strategy for the detection of clonal ALL cells. In the preliminary series of experiments previously mentioned (31), we had shown that sensitivity of detection of a particular clonal V-J rearrangement was lowered when clonal DNA was mixed with polyclonal T cell DNA. This result was interpreted as indicating competitive use of primers and/or polymerase by irrelevant amplifiable rearrangements. This was confirmed by further experiments using mixtures of two clonal DNAs whose rearrangements used the same $\mathrm{V}_{\boldsymbol{\gamma}}-\mathrm{J} \boldsymbol{\gamma}$ combination. The level of sensitivity of detection of the clone recognized by the antijunctional oligonucleotide correlated inversely with the percentage of irrelevant $\mathrm{TCR} \gamma$ rearrangements using the same V-J combination. The levels of detection on dilution into germline DNA and into $10 \%$ polyclonal T cell DNA were comparable, however, suggesting that the presence of low numbers of $T$ cells as in bone marrow aspirate would not be too deleterious (data not shown).

We therefore undertook to develop a strategy in which the amplification would be as specific as possible for one of the two alleles, in order to maximize the sensitivity of detection of clonal cells by specific AJO probes. Anti-V segment amplification oligonucleotides were therefore selected in order to exploit differences in nucleotide sequence between $\mathrm{V}_{\gamma}$ segments near their $3^{\prime}$ ends. The $V$ and $J$ segments involved in rearrangement had previously been determined from Southern blotting and probing with $\mathrm{Jg}$ and $\mathrm{Jd}$ probes $(11,28,32$, and data not shown). In some cases the efficacy of amplification was unsatisfactory and new primers were designed. The location of the primers eventually used, as well as the references describing the germline $V_{\gamma}$ sequences are shown in Table II. As we have previously demonstrated, the nucleotide sequences of $\mathrm{V}_{\gamma} 4 / \mathrm{V}_{\gamma} 2$ and $\mathrm{V}_{\gamma} 3 / \mathrm{V}_{\gamma} 5$ are $>98 \%$ homologous (14). It was therefore not possible to construct highly specific primers for those $V_{\gamma}$ segments.

The $\mathrm{V}_{\gamma}$ and $\mathrm{J} \gamma$ primers were used to PCR amplify presentation DNA from over $50 \mathrm{TCR} \gamma$ rearrangements in 31 cases of $T$ and $B$ lineage ALL, most of them being performed on DNA with distinct rearrangements on each TCR $\gamma$ alleles. It was possible to amplify rearrangements involving all $\mathrm{V}_{\gamma}$ segments known to be capable of producing a functional protein $\left(\mathrm{V}_{\gamma} 2\right.$, $3,4,5,8,9,10$, and 11) and rearrangements using $\mathrm{J} \gamma 1, \mathrm{~J} \gamma 2$, JP, and JP1 (Fig. $1 C$ ). An amplification oligonucleotide that recognized both $\mathrm{J}_{\gamma} 1$ and $\mathrm{J}_{\gamma} 2$ was used in cases using this segment. In all but those cases with $\mathrm{V}_{\gamma} 2-\mathrm{J} \gamma / \mathrm{V}_{\gamma} 4-\mathrm{J} \gamma$ configuration, specific amplification was obtained. A representative set of experiments analyzed by polyacrylamide gel electrophoresis is shown in Fig. $1 C$. Note that, as we have previously described for $\mathrm{V} \delta 1-\mathrm{J} \delta 1$ rearrangements (33), PCR amplification of rearrangements involving the same V-J combination on both alleles leads to formation of large fragments probably corresponding to heterodimers (Fig. $1 C$, lanes 7 and 8 ), although this has not been proven.

The $V_{\gamma}$-J $\gamma$ junctional sequences are clone specific. The validity of this approach for the detection of clonal cells is based on the assumption that junctional sequences are clone specific. Such specificity is to be expected if deletions and/or additions of nucleotides occur at random during $\mathrm{V}$-(D)- $\mathrm{J}$ recombination. This is clearly the case for TCR $\delta$ gene rearrangements in leukemic T cells ([33] and Fig. 3) and has been suggested to be true for TCR $\gamma$ gene rearrangements in a small number of established cell lines (reviewed in reference 13) and fresh ALL cells (11).

To analyze a more representative set of $\mathrm{TCR} \gamma$ rearrangements, we sequenced $52 \mathrm{~V}_{\gamma}$-J $\gamma$ junctions after PCR amplifcation of various $B$ and $T$ lineage leukemia DNAs obtained at presentation. Four TCR $\gamma$ rearrangements observed in relapsing patients (T31, T39, and T41) were also sequenced. These results will be discussed below. Nucleotide sequences are shown in Table I. Major junctional diversity was observed in the great majority of the $52 \mathrm{TCR} \gamma$ rearrangements. Nucleotide deletion of the $3^{\prime}$ part of $\mathrm{V}_{\gamma}$ segments ranged from 0 to 20 (mean 3.9 \pm SD 4.3). Deletions of the $5^{\prime}$ part of $\mathrm{J} \gamma$ seemed to be more extensive, ranging from 0 to 22 (mean 6.6 4 SD 4.9) (Table I). There was no correlation between the number of nucleotides deleted from the $V$ and the $J$ segments. In $16 / 52$ rearranged alleles no deletion of the $V$ segment was observed. Putative $P$ nucleotides (34) were noted in 8 of these cases (see Discussion). The same pattern was observed for all cases, there being no deletion in the $5^{\prime}$ end of the $\mathrm{J}$ segment (Table $\mathrm{I}$ ). Addition of nongermline encoded nucleotides ( $\mathrm{N}$ regions) were noted in all but two cases. The number of added nucleotides ranged from 0 to 17 (mean \pm SD, 5.9 \pm 3.9 ). The nucleotide composition of $\mathrm{N}$ regions was highly variable with a $\mathrm{GC}$ content of $55.1 \%$ (P nucleotides excluded from the calculation). No differences in the extent of deletion/addition or in the $\mathrm{GC}$ content of $\mathrm{N}$ regions were observed between junctional sequences involving different $\mathrm{V} \gamma$ segments. There was no difference in the GC content of in-frame and out-of-frame rearrangements.

The number of nucleotide deletions/additions was no different when T and B lineage ALLs were compared, nor was there any difference between immature (CD3-) and mature $(\mathrm{CD} 3+)$ T-ALLs. In contrast, comparison of CD3 $+\alpha \beta$ and $\gamma \delta$ expressing cases showed a lower number of added nucleotides in the latter group (Table I). Approximately one-third (36\%) of rearrangements were in-frame and free of stop codons and were considered as potentially functional. All junctional sequences were unique.

These data show that, although they are less extensive than $\mathrm{V} \delta 1-\mathrm{J} \delta 1$ junctions (33), TCR $\gamma$ junctional sequences can be considered as highly variable clone-specific markers in uncultured ALL cells irrespective of cell lineage and stage of differentiation.

Antijunctional TCR $\gamma$ or TCR oligonucleotides allow specific detection of clonal cells. We then undertook to determine whether oligonucleotides directed against junctional sequences (AJO) could specifically detect clonal cells.

We first verified that AJO were able to recognize their corresponding targets after PCR amplification. 21 AJO were synthesized and used as described in Methods. As expected, specific hybridization was observed in each case (Fig. 2 and data not shown).

We next examined the reactivity of AJO against PCR amplified DNA from various purified polyclonal T cell samples. These samples demonstrate extensive junctional diversity, at 


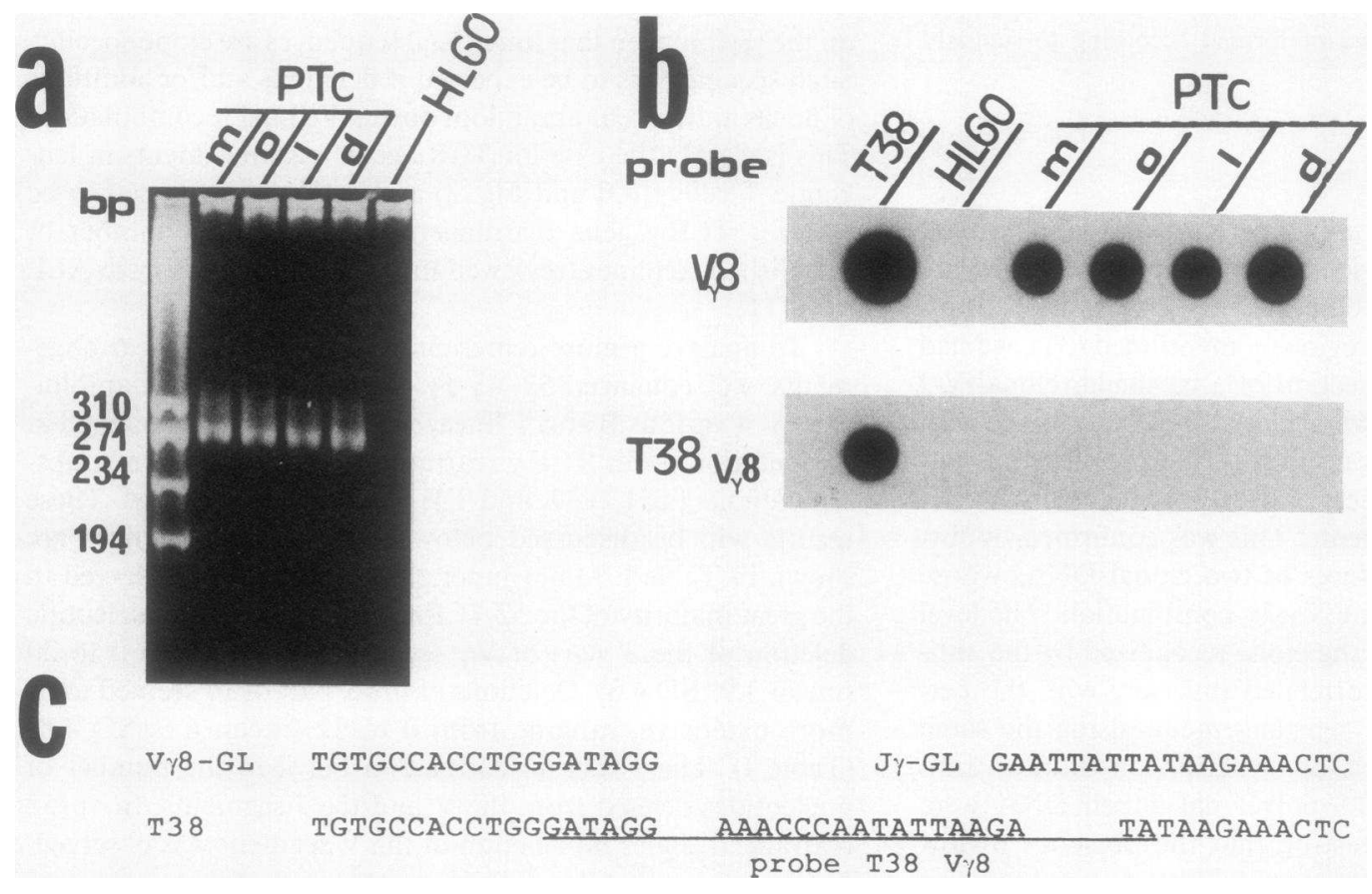

Figure 2. Specificity of AJOs. (a) Polyclonal T cell DNA from four healthy donors $(m, o, l$, and $d$ ) and DNA from the control HL60 cell line were PCR amplified using $\mathrm{V}_{\gamma} 8$ and $\mathrm{J} \gamma$ amplimers and further analyzed by PAGE. (b) Amplified DNA were dotted and hybridized with the TV $\gamma 8$ oligonucleotide (upper panel) and the T38 V 88 AJO (lower panel). (c) Nucleotide sequence of the $\mathrm{V} \gamma 8$-J $\gamma$ rearrangement from the T38 case. The sequence of the T38 AJO is underlined.

least for TCR $\gamma$ rearrangements (unpublished data), and therefore provide target samples in which the possibility of detecting a cross-hybridizing junctional rearrangement on the basis of chance alone is greater than in apparent remission bone marrow. A representative experiment is shown in Fig. 3. In no case was cross-hybridization detected. A polyclonal T cell DNA negative control is now included in all PCR experiments.

To further test the specificity of AJO, we analyzed the reactivity of several TCR $\gamma$ and TCR $\delta$ AJO probes against a panel of amplified tumor DNA all of which had undergone a

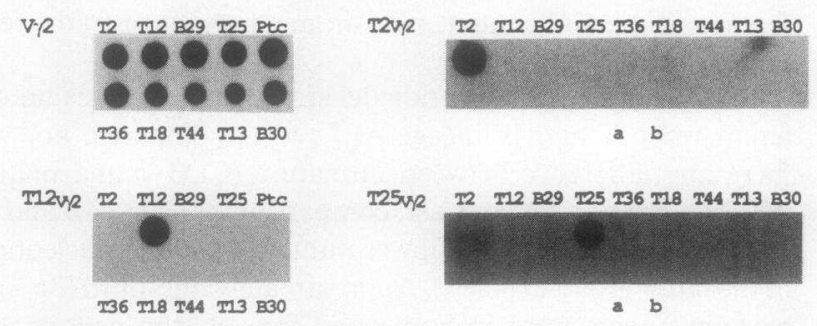

b

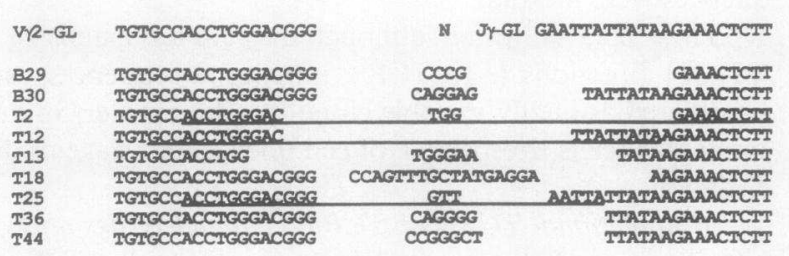

d

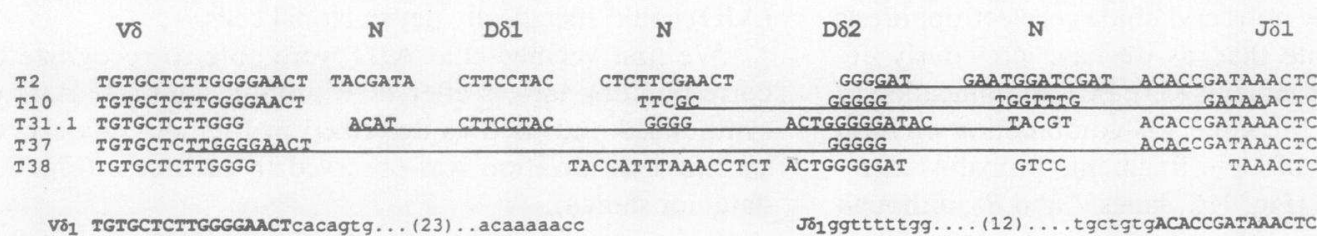

Figure 3. Specificity of TCR $\gamma \delta$ AJOs. (a) DNA from leukemic cells all of which had undergone $V_{\gamma} 2$ rearrangements and control polyclonal $\mathrm{T}$ cells were PCR amplified and hybridized with the $T V \gamma 2$ probe or with three TCR $\gamma$ AJOs (i.e., T2, T12, T25). $a$, T2 DNA

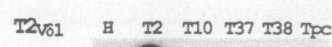
amplified with $\mathrm{V} \gamma 4$ and $\mathrm{J} \gamma$ primers; $b$, T12 DNA amplified with $\mathrm{V} \gamma_{\gamma} 4$ and $\mathrm{J} \gamma 1 / 2$ primers (used as controls). (b) Nucleotide sequences of the corresponding $\mathrm{V}_{\boldsymbol{\gamma}} 2-\mathrm{J} \boldsymbol{\gamma}$ rearrangements (P nucleotides not individualized). The sequences of the AJOs are underlined. ( $c$ and $d$ ) Similar experiments performed with $\mathrm{V} \delta 1$ and $J \delta 1$ amplimers (as previously described [33]) and TV $\delta 1$ or AJOs (T31, T2, T10, and T37) used as probes. $H$, control HL60 cell line; Tpc,

polyclonal T cells. Note that DNA from T31 samples both at presentation (left) and at relapse (right) hybridize with the $\alpha \mathrm{T} 31 \mathrm{~V} \delta 1$ AJO (T31 $V \delta 1$ panel). 
Table III. Detection of Minimal Residual Disease in Clinical Samples with AJOs

\begin{tabular}{|c|c|c|c|c|c|c|c|}
\hline \multirow[b]{2}{*}{ No.* } & \multicolumn{3}{|c|}{ Clinical sample } & \multicolumn{2}{|c|}{ TCR $\gamma$ AJO } & \multicolumn{2}{|c|}{ TCRס AJO } \\
\hline & & Sample & Time $^{\ddagger}$ & V level ${ }^{\ddagger}$ & Result & Level & Result \\
\hline \multirow[t]{3}{*}{ T19 } & $\mathbf{a}$ & cytapheresis & $1 \mathrm{mo}$ & V5 $10^{-4}$ & $\operatorname{Pos}\left(10^{-3}\right)$ & $10^{-5}$ & $\operatorname{Pos}\left(10^{-4}\right)$ \\
\hline & $\mathbf{b}$ & PB & $26 \mathrm{mo}$ & V5 $10^{-4}$ & Neg & $10^{-5}$ & Neg \\
\hline & c & $\mathbf{B M}$ & $26 \mathrm{mo}$ & V5 $10^{-4}$ & $\mathrm{Neg}$ & $10^{-5}$ & Neg \\
\hline \multirow[t]{2}{*}{ T38 } & $\mathbf{a}$ & PB & $12 \mathrm{mo}$ & $V 8<10^{-4}$ & $\operatorname{Pos}\left(10^{-1}\right)$ & $10^{-4}$ & $\mathrm{Neg}$ \\
\hline & $\mathrm{b}$ & $\mathbf{B M}$ & $12 \mathrm{mo}$ & $V 8<10^{-4}$ & $\operatorname{Pos}\left(10^{-1}\right)$ & $10^{-4}$ & $\mathrm{Neg}$ \\
\hline $\mathrm{T} 2$ & $\mathbf{a}$ & $\mathbf{B M}$ & $34 \mathrm{mo}$ & V2 $10^{-4}$ & $\mathrm{Neg}$ & $10^{-4}$ & Neg \\
\hline \multirow[t]{2}{*}{$\mathrm{T} 10$} & $\mathbf{a}$ & PB & $38 \mathrm{mo}$ & V9 $10^{-4}$ & $\mathrm{Neg}$ & $10^{-5}$ & $\mathrm{Neg}$ \\
\hline & b & BM & $38 \mathrm{mo}$ & V9 $10^{-4}$ & Neg & $10^{-5}$ & Neg \\
\hline T31 & $\mathbf{a}$ & cytapheresis & $1 \mathrm{mo}$ & V8 $10^{-4}$ & $\mathrm{Neg}$ & $10^{-4}$ & $\mathrm{Neg}$ \\
\hline
\end{tabular}

PB, peripheral blood; BM, bone marrow. In all cases DNA was extracted from Ficoll purified mononuclear cells. * PB and BM film examination indicated a complete remission at the time of studies in all cases. ${ }^{\ddagger}$ From the start of therapy; ${ }^{\S}$ level of sensitivity assesed by dilution analysis into 1/0.1 HL60/Polyclonal T cell DNA (see Methods and Fig. 3).

rearrangements involving a V-J combination identical to that of the tested AJO probe. Hybridization experiments for three TCR $\gamma$ and four TCR $\delta$ AJO are presented in Fig. 3, demonstrating the specificity of these probes.

Sensitivity of detection and demonstration of malignant cells in clinical samples. We next examined the sensitivity of detection by AJO in dilution experiments analyzed simultaneously with clinical DNA samples obtained at distinct stages during disease evolution in five patient with ALL (Table III).
As a reasonable approximation of bone marrow $T$ cell content, we performed dilutions of clonal DNA into a mixture of HL60 (myeloid cell line) and polyclonal $\mathrm{T}$ cell DNAs at a ratio of 10:1. One TCR $\gamma$ and one TCR $\delta$ AJO was used in all cases in order to determine the reproductibility of the level of sensitivity of detection and to exclude false positives.

Representative experiments are shown in Fig. 4 and Table III. In all cases the sensitivity was in the $10^{-4} / 10^{-5}$ range. Samples included blood, bone marrow and, in cases T19 and T31,

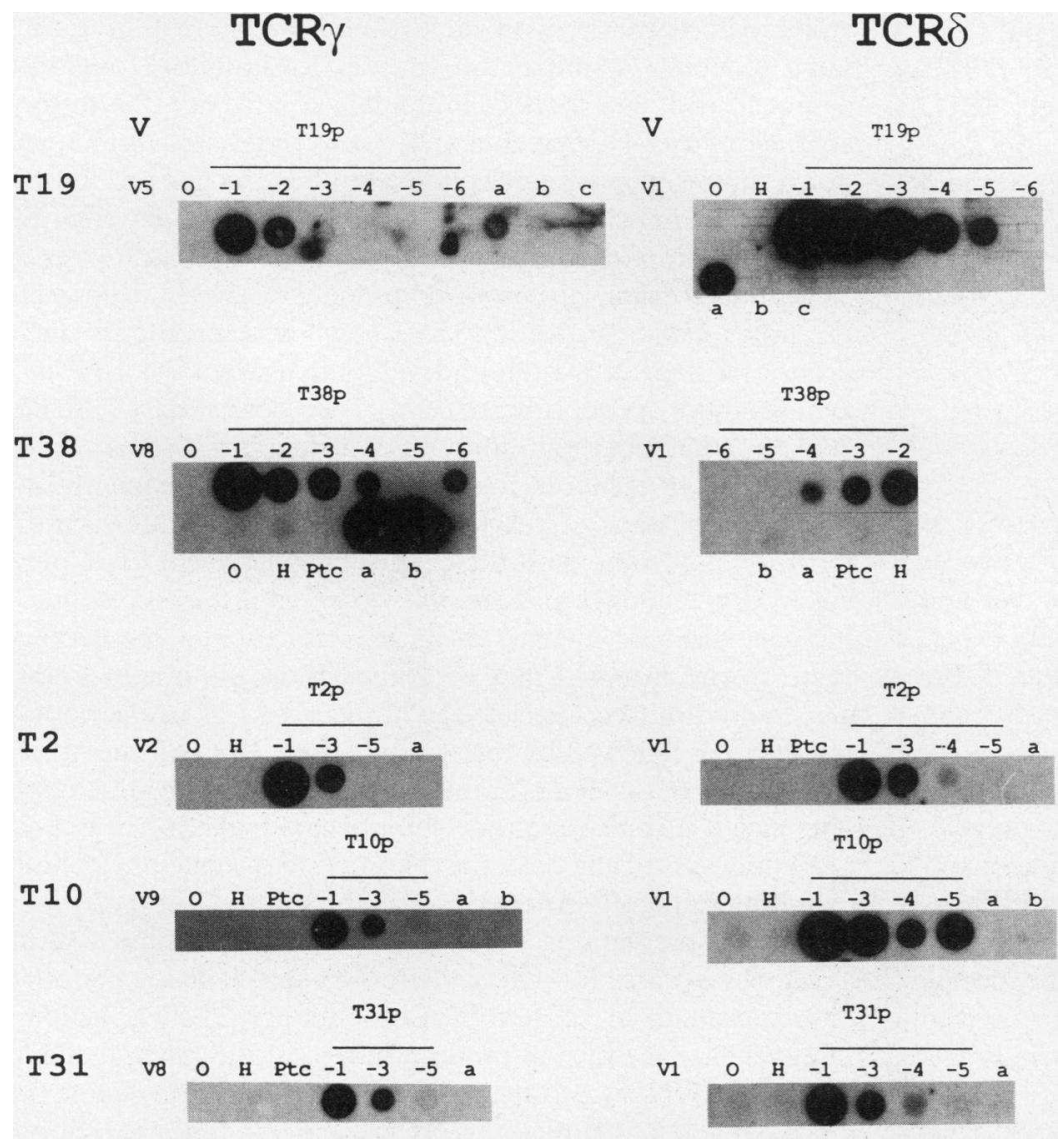

Figure 4. Sensitivity of detection by AJO of minimal disease in clinical samples. DNA from tumor cells obtained at presentation (quoted as 'case number' $p$ ) was diluted into a 10:1 mixture of HL60/polyclonal T cell DNA at various dilutions (10:1 to $10: 5$ or $10: 6)$ and amplified and further analyzed with DNA samples obtained during the evolution of the disease (samples marked $a, b$, or $c$; see Table III for definition). Dot blots were hybridized with AJO directed against the corresponding $\mathrm{TCR} \gamma \delta$ rearrangements. 
peripheral blood mononuclear cells containing occasional stem cells obtained by leukapheresis during postchemotherapy regeneration. For two patients (T10 and T19), longitudinal studies were performed including at least one sample obtained in apparent complete remission. In two cases (T19a, T38a, b; Fig. 4), positive hybridization with the corresponding AJO probe was observed, strongly suggesting the presence of residual malignant cells. Both positive clinical samples were taken early in remission. One of these patients (T38) relapsed soon afterwards. It is noteworthy that a subsequent sample taken from patient $\mathrm{T} 19$ two years later was negative with no evidence of disease at a $10^{-5}$ dilution. Two of three negative samples were taken later on in remission. In four of the five cases, similar results were found with both AJOs. There was however, a discrepancy in the results with the two AJOs in T38 (see below). It is noteworthy that some discrepancies in the evaluation of the number of malignant cells (in the range of one log dilution) were observed, showing that quantification should be considered as only approximate.

Limitations of AJO use for the detection of MRD. The use of AJO in detecting minimal residual disease assumes that an identical rearrangement(s) exists in all malignant cells and that no alteration of rearrangement patterns occurs between presentation and subsequent relapses. To test this hypothesis, nine cases of B (two cases, B13 and B5, not shown in Table I) or T lineage ALLs (seven cases, T14, 26, 31, 41, 38, 39, see Table I) were studied at presentation and at first relapse. 14 TCR $\gamma$ and 12 TCR $\delta$ alleles were analyzed (excluding germline alleles). In 2 instances, alterations were observed. In 1 case (T39) the $\mathrm{TCR}_{\gamma}$ genotype was $\mathrm{V}_{\gamma} 8 / \mathrm{V}_{\gamma} 8$ at presentation and $\mathrm{V} \gamma 8 / \mathrm{V}_{\gamma} 4$ at the first relapse. In another case (T38) a partial $\mathrm{V} \delta 1-\mathrm{J} \delta 1$ rearrangement was detected at presentation but complete deletion of this allele was demonstrated at relapse. This explains why the anti-TCR V $\delta 1$ AJO failed to detect MRD while the anti- $\mathrm{V} \gamma 8$ AJO was positive (see above).

Of those cases with an identical pattern of rearrangement on Southern blotting at presentation and relapse, 13 alleles $(10 \gamma, 3 \delta)$ were amplified and shown to have identically sized V-(D)-J junction by PAGE. Sequence analysis of 4 of these rearrangements ( $\mathrm{T} 31 \mathrm{~V} \delta 1$ [2 alleles], $\mathrm{T} 31 \mathrm{~V} \gamma 8, \mathrm{~T} 41 \mathrm{~V} \gamma 11)$ confirmed identical sequences (not shown).

\section{Discussion}

In this paper we show that AJOs, which recognize TCR $\gamma \delta$ V-(D)-J junctions, provide sensitive and specific clonal probes that can be used in the majority of cases of ALL of both T and $B$ cell lineage. We had previously shown in preliminary experiments (31) that it was possible to amplify a particular TCR $\gamma$ rearrangement and, by cloning the V-J junctions, construct an AJO that could detect residual clonal cells. There was, however, a discrepancy in the level of sensitivity of detection on dilution of clonal DNA into germline DNA and into polyclonal DNA. An additional disadvantage was that cloning of amplified products before sequencing can be relatively time consuming. It remained to demonstrate that TCR $\gamma$ junctional sequences in the majority of cases are sufficiently clone specific in ALL, to determine whether our strategy could be used in other TCR $\gamma \delta$ rearrangements, and finally to test the clinical applicability of our procedure.

By analysis of a large number of clonal neoplastic cells, we showed here that TCR $\gamma$ V-J junctional sequences are indeed clone specific. We have previously shown that direct sequencing of TCR $\delta$ rearrangements in ALL is feasible (33). In this study we analyzed over $50 \mathrm{TCR} \gamma$ alleles using the same strategy. The quality of sequence data obtained varied considerably depending on the $\mathrm{V}_{\gamma}$ segment amplified, but this did not appear to correlate with the quantity or quality of amplification as assessed by PAGE. Direct sequencing results were most satisfactory with $V_{\gamma} 9$ and $V_{\gamma} 2$ rearrangements. In contrast, it was not possible to directly sequence $\mathrm{V}_{\gamma} 4$ rearrangements for reasons that are not clear. This may relate to the fact that during this series of experiments we demonstrated a polymorphism at position 392 in the numbering system of Le Franc et al. (10) (5/10 C:5/10 T), which was situated in the center of the $\mathrm{TV}_{\gamma} 4$ oligonucleotide used as a sequencing primer. However, resisting of this priming oligonucleotide did not improve the quality of double-stranded sequence analysis. The advantages of double-stranded sequencing include its rapidity and the fact that any misincorporation of nucleotides, which occurs during PCR amplification, will not be detected since large numbers of sequences are read simultaneously, only a small proportion of which will contain the misincorporated sequence; this is not the case with sequence analysis after cloning of amplified products. We have found a high rate of misincorporation on single-stranded sequencing of cloned PCR products (11/2837; $0.4 \%$ ). Disadvantages of double-stranded sequencing include the fact that the quality of sequence obtained tends to be inferior, enough internal sequence must be available to enable the use of an internal primer, and in the majority of cases ${ }^{32} \mathrm{P}$ is required for labeling.

Analysis of the TCR $\gamma$ junctional sequences showed considerable heterogeneity, with no two clones demonstrating the same sequence. Comparison with TCR $\delta$ junctional regions demonstrated, as expected, much less complexity due to the absence of any D segments and, on average, less numerous nongermline encoded nucleotide additions. As has previously been shown in cell lines, the $\mathrm{N}$ region additions were slightly GC rich. Comparison of the TCR $\gamma \mathrm{N}$ regions in TCR $\gamma \delta$ and TCR $\alpha \beta$ expressing cases showed more extensive $\mathrm{N}$ regions in the latter cases, suggesting that these rearrangements may occur at a stage in lymphoid development when the TdT enzyme is more active. It has recently been observed by Lafaille et al. (34) that recurrent mono- or dinucleotides (also named $P$ nucleotides, $\mathbf{P}$ standing for palindrome) occur frequently in $\mathrm{V}$-(D)-J junctions of rearranging genes. These nucleotides form a palindrome with the immediately adjacent germlineencoded nucleotides and are only observed if the corresponding gene segment appears in its full sequence in the coding joint. It was proposed that such nucleotides are due to a single-strand dinucleotide cleavage of the $5^{\prime}$ end of the rearranging segment followed by the joining to the $3^{\prime}$ end of the other strand. One or two P nucleotides are observed in the junctional sequence if no subsequent deletion occurs (resulting in two $P$ nucleotides) or if the deletion is limited to a single nucleotide (resulting in one $\mathbf{P}$ nucleotide). Examination of our data confirm these observations. Putative $P$ nucleotides are observed in a number of cases for which the rearranging gene segment $(V$ or $\mathrm{J})$ appears in its full germline sequence ( $15 / 23$ alleles). Note however that the overall random nature of the junctional sequences is not greatly alterated by this phenomenon (Table I).

Having demonstrated that TCR $\gamma$ and $\delta$ junctional regions 
are highly clone specific, we then used AJOs to distinguish amplified clonal DNA from other clones using the same $\mathrm{V}$ and $\mathrm{J}$ segments and from polyclonal T cells. These AJOs were also capable of detecting clonal cells at a $10^{-4}-10^{-5}$ dilution in the presence of $10 \%$ polyclonal T cells. Since the initial quantity of DNA was $1 \mu \mathrm{g}$, this represents detection at the 1 to 10 cell level and is not therefore surprising if there is a one log variability in the level of sensitivity between experiments. The sensitivities of detection on amplification of TCR $\gamma$ and TCR $\delta$ were comparable, as one would expect. Analysis of clinical samples allowed us to demonstrate residual disease in two of five cases in apparent complete remission. While these clinical data are obviously preliminary, they do suggest that larger longitudinal studies of patients with ALL will provide much useful information on the evolution of this disease.

The choice of the rearrangement to be used as the clonal marker in our strategy may depend of the number of polyclonal $T$ cells present in the samples. We initially showed that the presence of irrelevant amplifiable rearrangements leads to a diminution in the level of sensitivity of detection of TCR $\gamma$ rearrangements (31). Experiments performed during this study suggest that this is due to consumption of reagents. In order to minimize this problem, it was important to develop a strategy that was as allele specific as possible. Using a bank of 11 oligonucleotides as amplification primers and 8 internal $\mathrm{V}$ segment-specific probes and sequencing primers, it was possible to specifically amplify all rearrangements other than those cases that demonstrated $\mathrm{V} \gamma 2$ or $\mathrm{V} \gamma 4$ rearrangements, since these two genes are greater than $98 \%$ homologous (14). The use of a V-specific amplification procedure minimizes the decrease of sensitivity due to contaminating polyclonal $\mathrm{T}$ cells. We show that the presence of $10 \%$ polyclonal DNA leads however to a minimal decrease, suggesting that the numbers of $\mathrm{T}$ lymphocytes found in remission bone marrow are unlikely to be a major problem. It does, however, limit the use of this TCR $\gamma$ amplification for the analysis of peripheral blood samples, although the small amount of DNA required means that the majority of polyclonal T cells could be removed by SRBC rosetting in all B lineage ALLs and in the few cases of CD2T-ALLs before analysis. If removing of polyclonal T cells is not practicable, it is preferable to use probes against V-D-J TCR $\delta$ sequences. The theoretical advantage of using this system is the fact that the majority of peripheral blood T cells ( $\alpha \beta$ expressing) have deleted TCR $\delta$ usually on both alleles (35). Biallelic deletions are observed in only $25 \%$ of either B or T ALLs (30). We have shown that TCR $\delta$ rearrangements involving the predominant $\mathrm{V} \delta 1-\mathrm{J} \delta 1$ rearrangement occurring in T-ALLs can be amplified. PCR amplification of TCR $\delta$ can also be used in $B$ lineage ALL since the predominant rearrangement in these cases involves V $\delta 2-\mathrm{D} \delta 3$ (11/22 rearranged alleles, unpublished observations). They can be PCR amplified using, for example the oligonucleotides shown in Table II. An alternative strategy for B lineage cases suggested by Yamada et al. (36) would be to use primers for the CDR3 region of the immunoglobulins. This has been shown to detect $1 / 10^{4}$ in HL60 DNA but the sensitivity in polyclonal B cell DNA was not analyzed.

A potential problem of PCR amplification-based strategies for the detection of minimal residual disease lies in the possibility of false positive results due to contamination of samples by amplified products (37). The allele-specific nature of the amplifications and the clone-specific AJOs used in the strategy described here will limit false positives to those samples contaminated with the patients own presentation DNA or amplified products, although contamination with a different patient sample undergoing rearrangement with the same $\mathrm{V}$ and $\mathrm{J}$ segments will lead to a diminution of sensitivity due to "competition" for oligonucleotides. To minimize these problems we feel that, in addition to all the general precautions necessary to avoid contamination (37), patients should, if possible, be analyzed with two separate AJOs.

A limitation specific to AJO-based strategies is the possibility of alteration in the rearrangement pattern, either due to emergence of a subclone or to clonal evolution in the predominant blast population. In certain cases coexistence of minor populations have been observed even at presentation by Southern blotting (38), limiting the use of AJOs for these clones in these cases. We have demonstrated alteration in $\sim 10 \%$ of TCR $\gamma \delta$ alleles in this study, which is similar to the incidence of clonal evolution of immunoglobulin heavy and light chains reported by Wright et al. (39). No patient, however, demonstrated evolution of more than one allele, suggesting that false negatives due to clonal evolution are unlikely if more than one AJO is used.

An alternative strategy based on the use of PCR amplification of TCR $\gamma$ or TCR $\delta$ junctional regions has been briefly reported by Tyko et al. (40). It is similar to that described here in that the presentation DNA is amplified, albeit using consensus primers, and sequenced after cloning of the amplified products. The junctional region of the TCR $\gamma$ rearrangement is then used as a target for a second "clone-specific" amplification using a junctional-specific amplification oligonucleotide with the $3^{\prime}$ end of the oligonucleotide directed to the $\mathrm{N}$ nucleotides. These amplified fragments were then analyzed with $\mathrm{V} \gamma$, but not clone-specific probes. This strategy has the theoretical advantage of only amplifying the clonal rearrangement. To verify that the fragments amplified are indeed those of the original clone, it would be preferable to be able to construct an additional internal AJO clone-specific probe that does not overlap with the amplification antijunctional oligonucleotide. This is possible with the extensive junctional diversity of complete V-D-J TCR $\delta$ rearrangements, as found predominantly in $T$ lineage but not in B lineage ALL. It's use for TCR $\gamma$ rearrangements is however limited by the more restricted nature of these junctions, as shown here. Moreover, the highly AT-rich nature of the $5^{\prime}$ end of TCR $\gamma \mathrm{J} 1 / 2$ segments, as found in the vast majority of $\mathrm{TCR} \gamma$ rearrangements, means that the temperature of these antijunctional oligonucleotides will be low. Since all specificity in this strategy must occur at the time of amplification, the disparity of the temperatures of the anti-V and antijunctional oligonucleotides will limit specificity. We have found that the use of this strategy is associated with nonspecific amplification of polyclonal $T$ cells in all but highly stringent conditions of amplification, and feel that this limits the use of this method in practice.

In practical terms, the method which we described here takes $\sim 11 \mathrm{~d}$ for the first step (obtaining the specific AJO). This includes Southern blot analysis of presentation DNA (8 d), initial PCR amplification (1 d), and direct sequencing (2 d). This estimate depends on the availability of commercially manufactured oligonucleotides, and is obviously minimized if oligonucleotides are synthesized and purified in the laboratory. Specific AJOs can be synthesized once and stored for 
subsequent use for the same patient during follow-up. Testing of clinical samples (i.e., amplification of remission DNA) takes only a few hours.

Our strategy could be shortened at several stages. Firstly, PCR based assignment of $V$ and $J$ segments will obviate the need for Southern blot analysis. Secondly, the use of uncharacterized, labeled, amplified presentation DNA fragments could be used as clone-specific probes as recently shown for the $\mathrm{V} \delta 1-\mathrm{J} \delta 1$ rearrangement by Hansen-Hagge et al. (41). These modifications of the use of AJOs may render our strategy useable in less specialized clinical laboratories, allowing the longitudinal study of large numbers of patients in order to assess the prognostic significance of low levels of persistent clonality.

\section{Acknowledgments}

Dr. Macintyre is supported by a joint fellowship from the Leukaemia Research Fund/Institut Nationale de la Santé et de la Recherche Médicale. This work is supported by grants from the "Ligue Nationale Contre le Cancer" and from "Assistance Publique-Hôpitaux de Paris."

\section{References}

1. Campana, D., and G. Janossy. 1990. Critical analysis of detecting minimal residual leukemia. In Acute Lymphoblastic Leukemia. Alan R. Liss, editor. 111-128.

2. Korsmeyer, S. J. 1987. Antigen receptor genes as molecular markers of lymphoid neoplasms. J. Clin. Invest. 79:1291-1295.

3. Saiki, R. K., S. Scharf, F. Faloona, K. B. Mullis, G. T. Horn, H. A. Erlich, and N. Arnheim. 1985. Enzymatic amplification of $\beta$ globin genomic sequences and restriction site analysis for diagnosis of sickle cell anemia. Science (Wash. DC). 230:1350-1354.

4. Lee, M., K. Chang, F. Cabanillas, E. Freireich, J. Trujillo, and S. Stass. 1987. Detection of minimal residual cells carrying the $t(14 ; 18)$ by DNA sequence amplification. Science (Wash. DC). 237:175-178.

5. Kawasaki, E., S. Clark, M. Coyne, S. Smith, R. Champlin, O. Witte, and F. McCormick. 1988. Diagnosis of chronic myeloid and acute lymphocytic leukemias by detection of leukemia-specific mRNA sequences amplified in vitro. Proc. Natl. Acad. Sci. USA. 85:56985702.

6. Lewis, S., and M. Gellert. 1989. The mechanism of antigen receptor gene assembly. Cell. 59:585-588.

7. Davis, M. M., and P. J. Bjorkman. 1988. T-cell antigen receptor genes and T-cell recognition. Nature (Lond.). 334:395-402.

8. Raulet, D. H. 1989. The structure, function, and molecular genetics of the $\gamma \delta \mathrm{T}$ cell receptor. Ann. Rev. Immunol. 7:175-207.

9. Lefranc, M. P., A. Forster, and T. Rabbitts. 1986. Rearrangement of two distinct $\mathrm{T}$-cell gamma chain variable region genes in human DNA. Nature (Lond.). 319:420-422.

10. Lefranc, M. P., A. Forster, R. Baer, M. Stinson, and T. H. Rabbitts. 1986. Diversity and rearrangement of the human $T$ cell rearranging gamma genes: nine germ-line variable genes belonging to two subgroups. Cell. 45:237-246.

11. Chen, Z., M. P. Font, P. Loiseau, J. C. Bories, N. Duparc, L. Degos, M. P. Lefranc, and F. Sigaux. 1988. The $V_{\gamma}$ locus: cloning of new segments and study of $\mathrm{V} \gamma$ rearrangements in neoplastic $B$ and $T$ cells. Blood. 72:776-783.

12. Forster, A., S. Huck, N. Ganem, M. P. Lefranc, and T. Rabbitts. 1988. New subgroups in the human $\mathrm{T}$ cell rearranging $\mathrm{V}_{\gamma}$ gene locus. EMBO (Eur. Mol. Biol. Organ.) J. 6:1945-1950.

13. Huck, S., P. Dariavach, and M. P. Lefranc. 1988. Variable region genes in the human T-cell rearranging gamma (TRG) locus: V-J junction and homology with the mouse genes. EMBO (Eur. Mol. Biol. Organ.) J. 7:719-726.
14. Font, M. P., Z. Chen, J. C. Bories, N. Duparc, P. Loiseau, L. Degos, H. Cann, D. Cohen, J. Dausset, and F. Sigaux. 1988. The V $\gamma$ locus of the human T-cell receptor $\gamma$ gene: repertoire polymorphism of the first variable gene segment subgroup. J. Exp. Med. 168:1383-1394.

15. Quertermous, T., W. Strauss, C. Murre, D. Dialynas, J. Strominger, and J. Seidman. 1986. Human T-cell $\gamma$ genes contain N segments and have marked junctional variability. Nature (Lond.). 322:184-187.

16. Quertermous, T., W. M. Strauss, J. J. M. Van Dongen, and J. Seidman. 1987. Human $T$ cell $\gamma$ chain joining regions and $T$ cell development. J. Immunol. 138:2687-2690.

17. Huck, S., and M. P. Lefranc. 1987. Rearrangements to the JP1, JP and JP2 segments in the human T-cell rearranging gamma gene (TRG) locus. FEBS (Fed. Eur. Biochem. Soc.) Lett. 224:291-295.

18. Hata, S., M. Brenner, and M. Krangel. 1987. Identification of putative human T cell receptor $\delta$ complementary DNA clones. Science (Wash. DC). 238:678-682.

19. Takihara, Y., D. Tkachuk, E. Michalopoulos, E. Champagne, J. Reiman, M. Minden, and T. Mak. 1988. Sequence and organization of the diversity, joining and constant region genes of the human T-cell $\delta$ chain gene. Proc. Natl. Acad. Sci. USA. 85:6097-6101.

20. Satyanarayana, K., S. Hata, P. Devlin, M. G. Roncarolo, E. De Vries, H. Spits, J. L. Strominger, and M. S. Krangel. 1988. Genomic organization of the human T cell receptor $\alpha / \delta$ locus. Proc. Natl. Acad. Sci. USA. 85:8166-8170.

21. Hockett, R. D., J. P. de Villartay, K. Pollock, D. G. Poplack, D. I. Cohen, and S. J. Korsmeyer. 1988. Human T-cell antigen receptor (TCR) $\delta$-chain locus and elements responsible for its deletion are within the TCR $\alpha$-chain locus. Proc. Natl. Acad. Sci. USA. 85:96949698.

22. Dariavach, P., and M. Lefranc. 1989. First genomic sequence of the human T-cell receptor $\delta 2$ gene (TRDV2). Nucl. Acids Res. $17: 4880$.

23. Boehm, T., L. Buluwela, D. Williams, L. White, and T. H. Rabbitts. 1988. A cluster of chromosome $11 \mathrm{p} 13$ translocation found via distinct D-D and D-D-J rearrangements of the human T cell receptor $\delta$ chain gene. EMBO (Eur. Mol. Biol. Organ.) J. 7:2011-2017.

24. Isobe, M., G. Russo, F. G. Haluska, and C. Croce. 1988. Cloning of the gene encoding the $\delta$ subunit of the human T-cell receptor reveals its physical organization within the $\alpha$-subunit locus and its involvement in chromosome translocations in T-cell malignancy. Proc. Natl. Acad. Sci. USA. 85:3933-3937.

25. Hata, S., K. Satyanatrayana, P. Delvin, H. Band, J. McLean, J. L. Strominger, M. B. Brenner, and M. Krangel. 1988. Extensive junctional diversity of rearranged human $T$ cell receptor $\delta$ genes. Science (Wash. DC). 240:1541-1544.

26. Hata, S., M. Clabby, P. Devlin, H. Spits, J. Devries, and M. Krangel. 1989. Diversity and organization of human T cell receptor $\delta$ variable gene segments. J. Exp. Med. 169:41-57.

27. Loh, E. Y., J. F. Elliott, S. Cwirla, L. L. Lamier, and M. M. Davis. 1989. Polymerase chain reaction with single-sided specificity: analysis of T cell receptor $\delta$ chain. Science (Wash. DC). 243:217-220.

28. Chen, Z., D. Le Paslier, J. Dausset, L. Degos, G. Flandrin, D. Cohen, and F. Sigaux. 1987. Human T-cell rearranging genes gamma are frequently rearranged in B-lineage acute lymphoblastic leukemias but not in chronic B-cell proliferations. J. Exp. Med. 165:1000-1015.

29. Hara, J., S. H. Benedict, E. Champagne, Y. Takihara, T. Mak, M. Minden, and E. W. Gelfand. 1988. T cell receptor $\delta$ gene rearrangements in acute lymphoblastic leukemia. J. Clin. Invest. 82:1974-1982.

30. Loiseau, P., P. Guglielmi, D. Le Paslier, E. MacIntyre, A. Gessain, J. C. Bories, G. Flandrin, Z. Chen, and F. Sigaux. 1989. Rearrangements of the T-Cell receptor $\delta$ gene in T-Acute lymphoblastic leukemia cells are distinct from those occurring in B-lineage acute lymphoblastic leukemia and preferentially involve one Vd gene segment. J. Immunol. 142:3305-3311.

31. d'Auriol, L., E. Macintyre, F. Galibert, and F. Sigaux. 1989. In vitro amplification of $\mathrm{T}$-cell $\gamma$ genes rearrangements: a new tool for the 
assessment of minimal residual disease in acute lymphoblastic leukemias. Leukemia (Baltimore). 3:155-158.

32. Le Paslier, D., Z. Chen, P. Loiseau, D. Cohen, and F. Sigaux. 1987. T cell rearranging gene $\gamma$ : diversity and mRNA expression in fresh cells from $T$ cell acute lymphoblastic leukemia. Blood. 70:637646.

33. Macintyre, E., L. d'Auriol, F. Amesland, P. Loiseau, Z. Chen, L. Boumsell, F. Galibert, and F. Sigaux. 1989. Analysis of junctional diversity in the preferential $\mathrm{V} \delta 1-\mathrm{J} \delta 1$ rearrangement in fresh T-cell acute lymphoblastic leukemic cells by in vitro gene amplification and direct sequencing. Blood. 74:2053-2061.

34. Lafaille, J. J., A. DeCloux, M. Bonneville, Y. Takagaki, and S. Tonegawa. 1989. Junctional sequences of $T$ cell receptor $\gamma \delta$ genes: implications for gd $\mathrm{T}$ cell lineages and for a novel intermediate of V-(D)-J joining. Cell. 59:859-870.

35. Kumar, V., J. L. Urban, and L. Hood. 1989. In individual T cells one productive $\alpha$ rearrangement does not appear to block rearrangement at the second allele. J. Exp. Med. 170:2183-2188.

36. Yamada, M., S. Hudson, O. Tournay, S. Bittenbender, S. S. Shane, B. Lange, Y. Tsujimoto, A. J. Caton, and G. Rovera. 1989. Detection of minimal disease in hematopoietic malignancies of the
B-cell lineage by using third-complementarity-determining region (CDR-III)-specific probes. Proc. Natl. Acad. Sci. USA. 86:5123-5127.

37. Kwok, S., and R. Higuchi. 1989. Avoiding false positives with PCR. Nature (Lond.). 339:237-238.

38. Bird, J., N. Galili, M. Link, D. Stites, J. Sklar. 1988. Continuing rearrangement but absence of somatic hypermutation in immunoglobulin genes of human B cell precursor leukemia. J. Exp. Med. 168:229-245.

39. Wright, J., D. Poplack, A. Backshi, G. Reaman, D. Cole, J. Jensen, and S. Korsmeyer. 1987. Gene rearrangements as markers of clonal variation and minimal residual disease in acute lymphoblastic leukemia. J. Clin. Oncol. 5:735-742.

40. Tycko, B., J. D. Palmer, M. P. Link, S. D. Smith, and J. Sklar. 1989. Polymerase chain reaction amplification of rearranged antigen receptor genes: possible application for detection of minimal residual disease in acute lymphoblastic leukemia. In Molecular Diagnosis of Human Cancer. M. Furth and M. Greaves, editors. Cold Spring Harbor Laboratory (CSH), Cold Spring Harbor, NY. 47-52.

41. Hansen-Hagge, T. E., S. Yokota, and C. R. Bartram. 1989. Detection of minimal residual disease in acute lymphoblastic leukemia by in-vitro amplification of rearranged T-cell receptor $\delta$ chain sequences. Blood. 74:1762-1767. 